\title{
Lumbar total disc arthroplasty: outdated surgery or here to stay procedure? A systematic review of current literature
}

\author{
Matteo Formica $^{1} \cdot$ Stefano Divano $^{1} \cdot$ Luca Cavagnaro $^{1} \cdot$ Marco Basso $^{1}$. \\ Andrea Zanirato $^{1} \cdot$ Carlo Formica $^{2} \cdot$ Lamberto Felli $^{1}$
}

Received: 11 January 2017/ Accepted: 11 June 2017/Published online: 6 July 2017

(c) The Author(s) 2017. This article is an open access publication

\begin{abstract}
Background The purpose of this study was to summarize the available evidence about total lumbar disc replacement (TDR), focusing our attention on four main topics: clinical and functional outcomes, comparison with fusion surgery results, rate of complications and influence on sagittal balance.

Materials and methods We systematically searched Pubmed, Embase, Medline, Medscape, Google Scholar and Cochrane library databases in order to answer our four main research questions. Effective data were extracted after the assessment of methodological quality of the trials. Results Fifty-nine pertinent papers were included. Clinical and functional scores show statistically significant improvements, and they last at all time points compared to baseline. The majority of the articles show there is no significant difference between TDR groups and fusion groups. The literature shows similar rates of complications between the two surgical procedures.

Conclusions TDR showed significant safety and efficacy, comparable to lumbar fusion. The major advantages of a lumbar TDR over fusion include maintenance of segmental motion and the restoration of the disc height, allowing patients to find their own spinal balance. Disc arthroplasty
\end{abstract}

Stefano Divano

ste.divano@hotmail.com

1 Clinica Ortopedica-IRCCS Azienda Ospedaliera Universitaria San Martino-IST, Istituto Nazionale per la Ricerca sul Cancro, Largo Rosanna Benzi, 10, 16132 GENOVA, GE, Italy

2 IRCCS Istituto Ortopedico Galeazzi, Via Riccardo Galeazzi 4, 20161 MILAN, MI, Italy could be a reliable option in the treatment of degenerative disc disease in years to come.

Level of evidence II.

Keywords Total disc replacement - Lumbar disc arthroplasty · Degenerative disc disease - Outcomes . Complications $\cdot$ Sagittal balance

\section{Introduction}

Lumbar degenerative disc disease (DDD) is one of the most important causes of low back pain, disability and medical consultations in Western countries and imposes huge economic burdens worldwide.

Most patients suffering from low back pain improve satisfactorily without surgery, but $1-5 \%$ of them do not respond to appropriate nonsurgical care, such as muscle strengthening, physical therapy, massage, manipulation, weight control and analgesia, and may be candidates for surgical treatment $[1,2]$.

Besides surgical techniques, several biological approaches, including the injection of biological substances such as growth factors, bioengineering approaches, and cell or gene therapies have been tested in either preclinical or clinical contexts [3].

Actually, interbody fusion that provides solid anterior support is the gold standard in the treatment of degenerative disc disease.

The fusion of the motion segment eliminates abnormal motion and unburdens loading on pathologic disc tissues, thereby reducing pain and improving quality of life [4].

However, long-term results are sometimes suboptimal in terms of pain relief, and various fusion-related 
complications such as incorrect placement of screws, breakage of metallic implants, and nonunion have been observed during follow-up for a long time.

Furthermore, there are common surgery complications, such as pseudoarthrosis, with an incidence of $16 \%$, and iliac crest bone graft donor site pain, with an incidence of $9 \%$ [5].

Also, adjacent segment disease (ASD) and dissociation between fusion rate and clinical success rate have received more serious attention from surgeons over time [6].

A viable alternative is total disc replacement (TDR), which has increased in popularity in recent decades and has been developed to preserve motion, and possibly reduce adjacent-level degeneration [6].

The aim of our study was to systematically review the available literature on lumbar total disc replacement in patients with chronic low back pain due to DDD, focusing our attention on effectiveness, safety, complication rates and influence of TDR in spinal balance.

\section{Materials and methods}

We performed a systematic review of the available English literature in order to answer four main research questions:

1. What is the evolution of DDD following total disc replacement surgery in terms of pain relief and functional outcomes?

2. What is the effectiveness of total disc replacement surgery compared to other treatments?

3. What is the safety and rate of complications of total disc replacement surgery?

4. How does total disc replacement surgery influence sagittal balance?

The Pubmed, Embase, Medline, Medscape, Google Scholar and Cochrane library databases were screened for relevant studies. The search strategy consisted of a combination of the following keywords: total disc replacement, lumbar disc arthroplasty, degenerative disc disease, outcomes, complications, sagittal balance. We included clinical studies with a follow-up greater than 24 months and with a cohort of patients greater than 20. Only papers related to lumbar total disc replacement were included in our analysis. Non-pertinent manuscripts were excluded. Exclusion criteria were: in vitro studies, case report and review or meta-analysis. We carefully examined reference lists from previous reviews or meta-analysis in order not to miss pertinent papers. The search was limited to studies published in English.

Two reviewers (SD and AZ) independently screened the titles and abstracts from all identified articles to assess their appropriateness to the research focus. In case of conflict among reviewers, a collegial evaluation with remaining authors was performed. References from the identified articles were checked in order not to miss any relevant articles.

All titles and abstracts that met our keywords were examined. The flow diagram illustrates the review process (Fig. 1).

\section{Results}

A total of 1022 articles were identified, 444 duplicates were removed.

Among 578 eligible articles, we selected only those matching our inclusion criteria.

During the selection of papers, no cases of conflict between two authors were reported.

Fifty-nine manuscripts were finally included and fully evaluated. Table 1 summarizes clinical and radiographic outcomes after lumbar TDR in DDD.

\section{What is the evolution of DDD following total disc replacement surgery in terms of pain relief and functional outcomes?}

Total VAS and ODI scores statistically decreased from preoperative to 1-2 years after surgery.

Although these scores increased until the last follow-up, they remained significantly lower than the preoperative values.

Schätz et al. [10] reported no significant differences, in terms of VAS and ODI improvement, between single-level and multi-level subgroups.

On the other hand, Siepe et al. [46] observed that postoperative outcome was significantly inferior following bisegmental disc replacements at L4-L5/L5-S1 with a considerably higher complication rate when compared with monosegmental TDR procedures.

Moreover, they highlighted VAS and ODI deterioration when disc replacement was performed at the lumbosacral junction, while most of other articles do not show difference depending on operated level.

Tohmeh et al. [14] showed there was a significant reduction in medication usage from baseline to last followup.

Ziegler et al. [25] examined neurological status, defined as the maintenance or improvement of patient responses to all neurological criteria: sensory and motor status, reflexes, and straight-leg test.

At 2 years of follow-up, the TDR group was statistically superior to the fusion group, with $91.2 \%$ success (135 of 148 patients) compared to $81.4 \%$ (57 of 70 patients), respectively. 


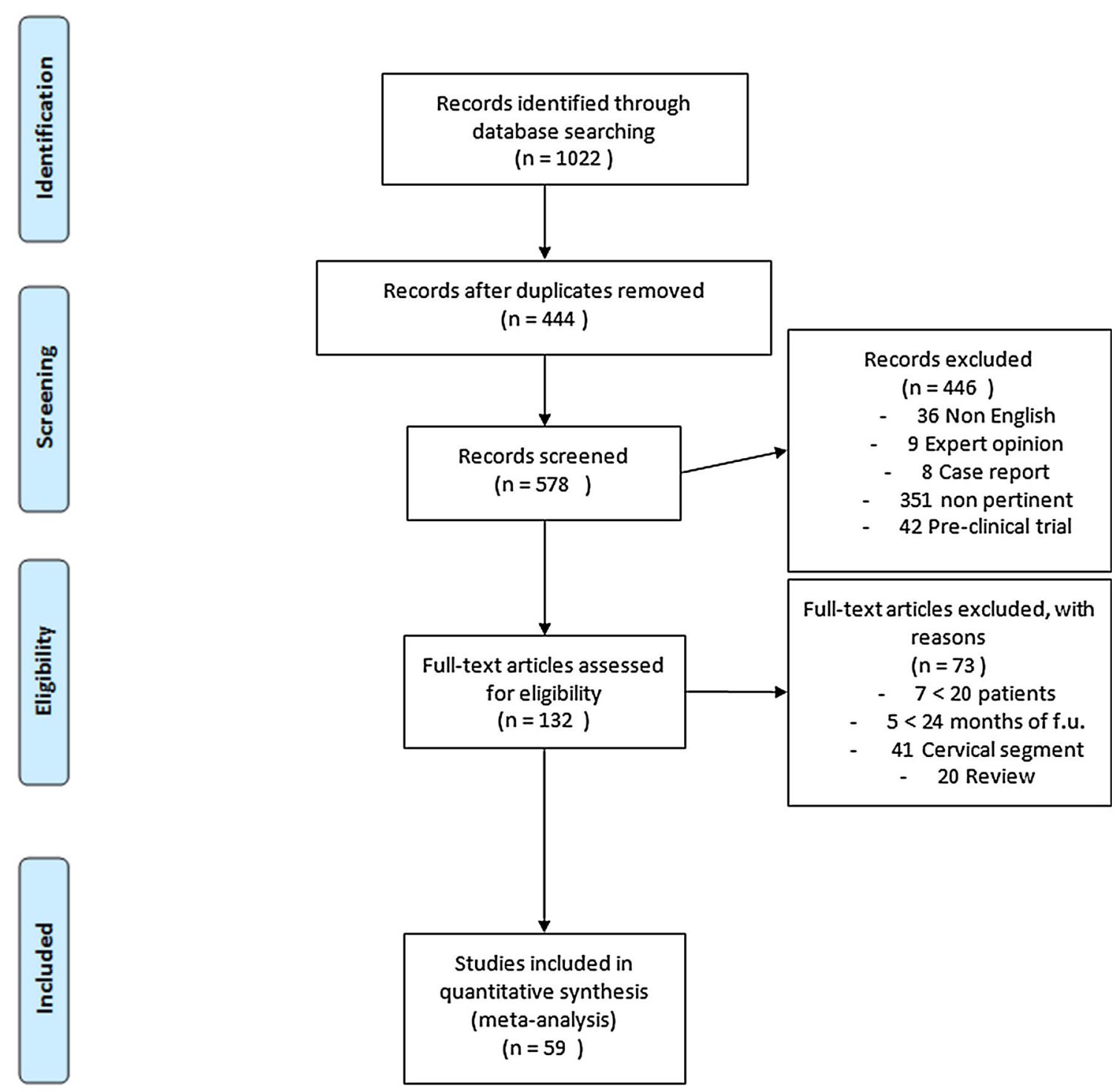

Fig. 1 The PRISMA 2009 flow diagram illustrates the review process, the number of the studies identified, included and excluded

The literature suggests that there is no significant difference, in terms of clinical outcomes, between various prostheses.

Pettine et al. [32] showed similar improvement, in terms of VAS and ODI scores for the Kineflex Disc group and Charité group at 2 years of follow-up (56.80, 37.30 and $54.43,38.40$, respectively).

David et al. [47] showed how $89.6 \%$ of patients returned to work after surgery, including $77.8 \%$ of patients working in hard labor employment, and $96.7 \%$ working in sedentary or light duty employment before surgery.

The correct positioning of TDR is crucial. McAfee et al. [60] showed us that mean ODI and VAS scores improved with the degree of technical accuracy.

In conclusion, many studies suggest pain relief, improvement in functional status and patient satisfaction after TDR surgery.
Unfortunately, detailed information about outcome measurement is often lacking. Moreover, the majority of the included studies were uncontrolled ones. Indeed, the quality of these studies is not sufficient to draw definite conclusions about pain relief and functional outcomes after TDR surgery.

\section{What is the effectiveness of total disc replacement surgery compared to other treatments?}

Although TDR achieved optimal outcomes, it is essential to compare these results with the outcomes obtained with the gold standard technique (fusion surgery).

Nearly every work shows similar patterns of two main clinical parameters, VAS and ODI scores: both techniques offered significant improvements. 


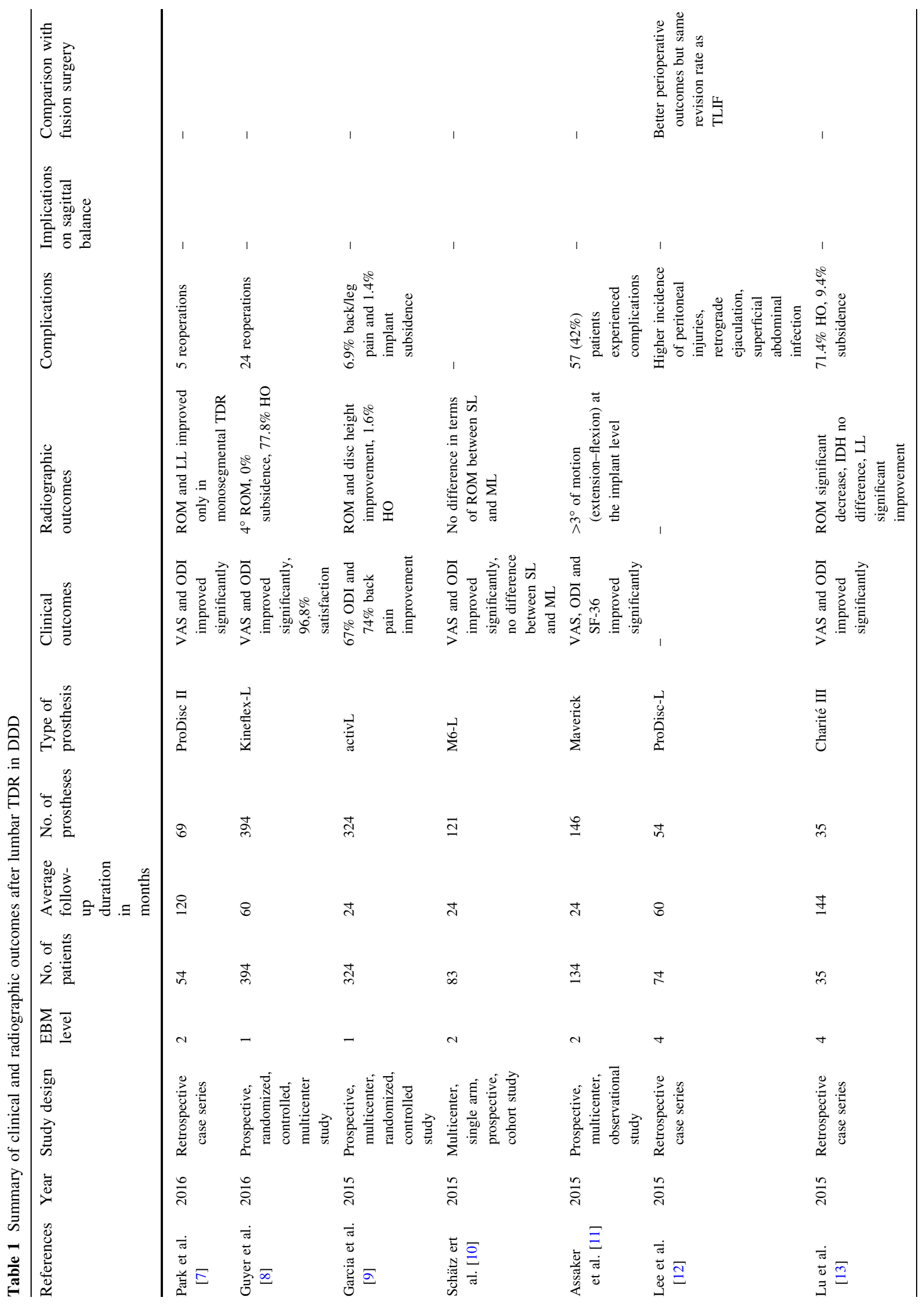




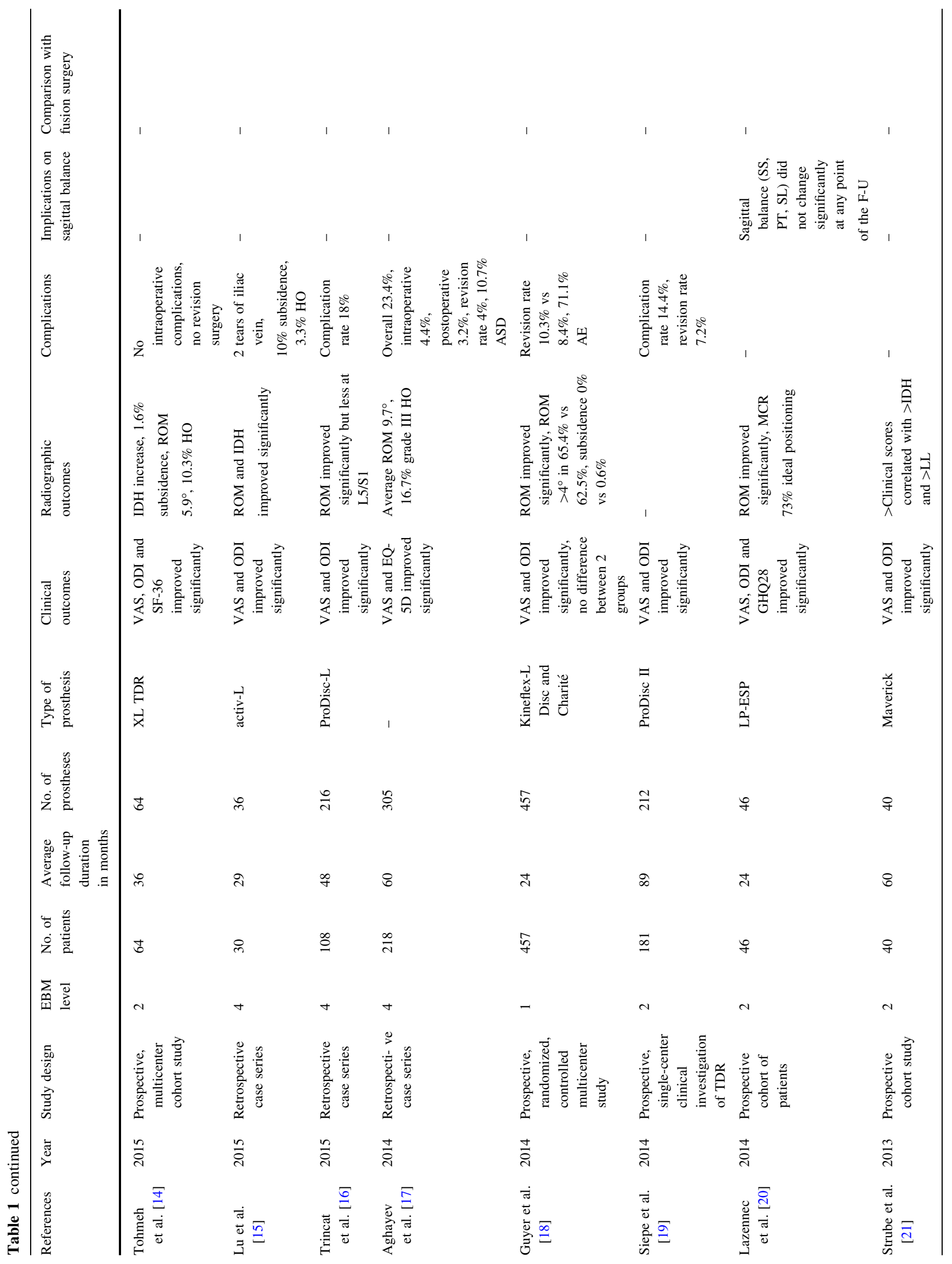




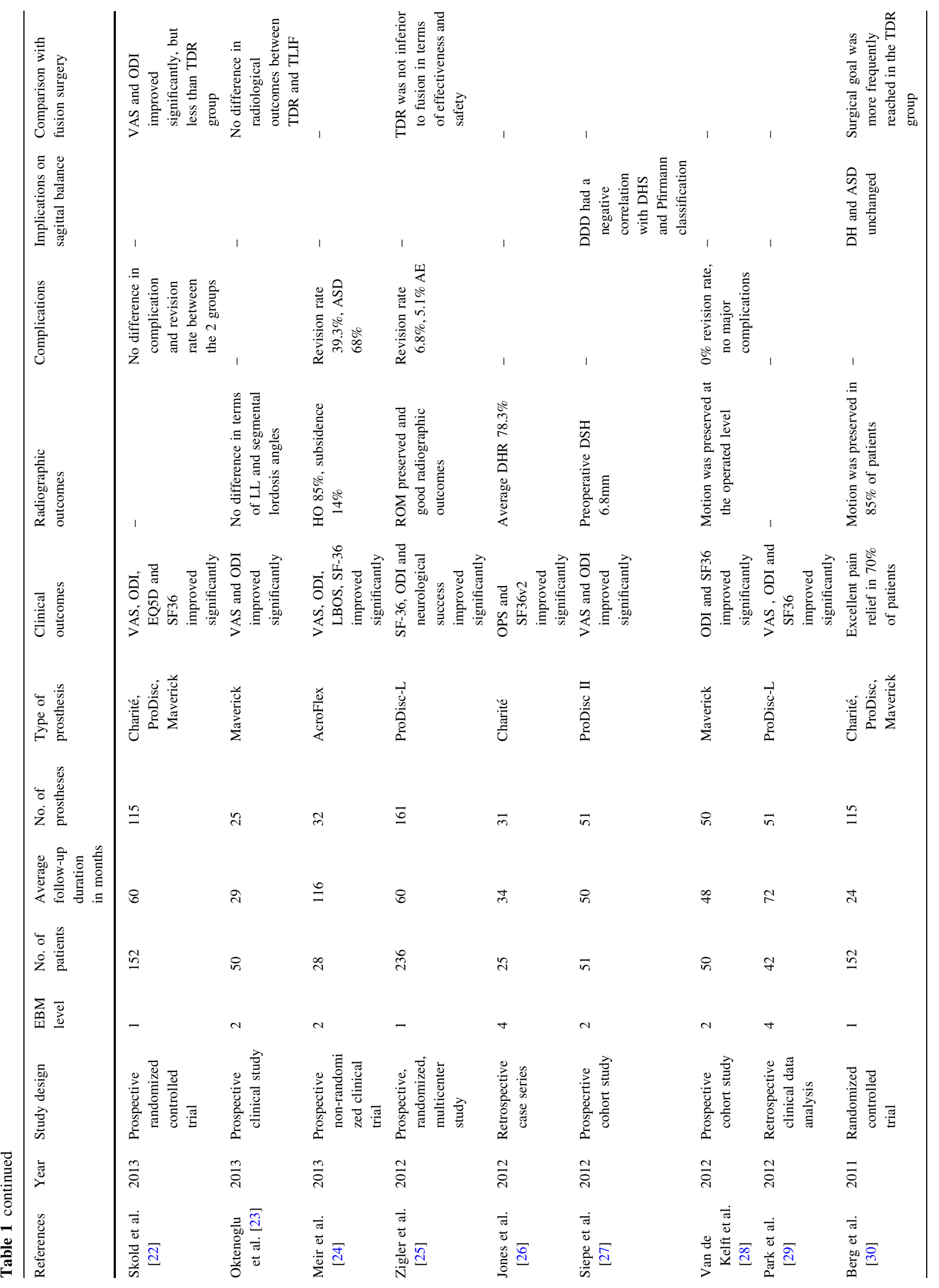




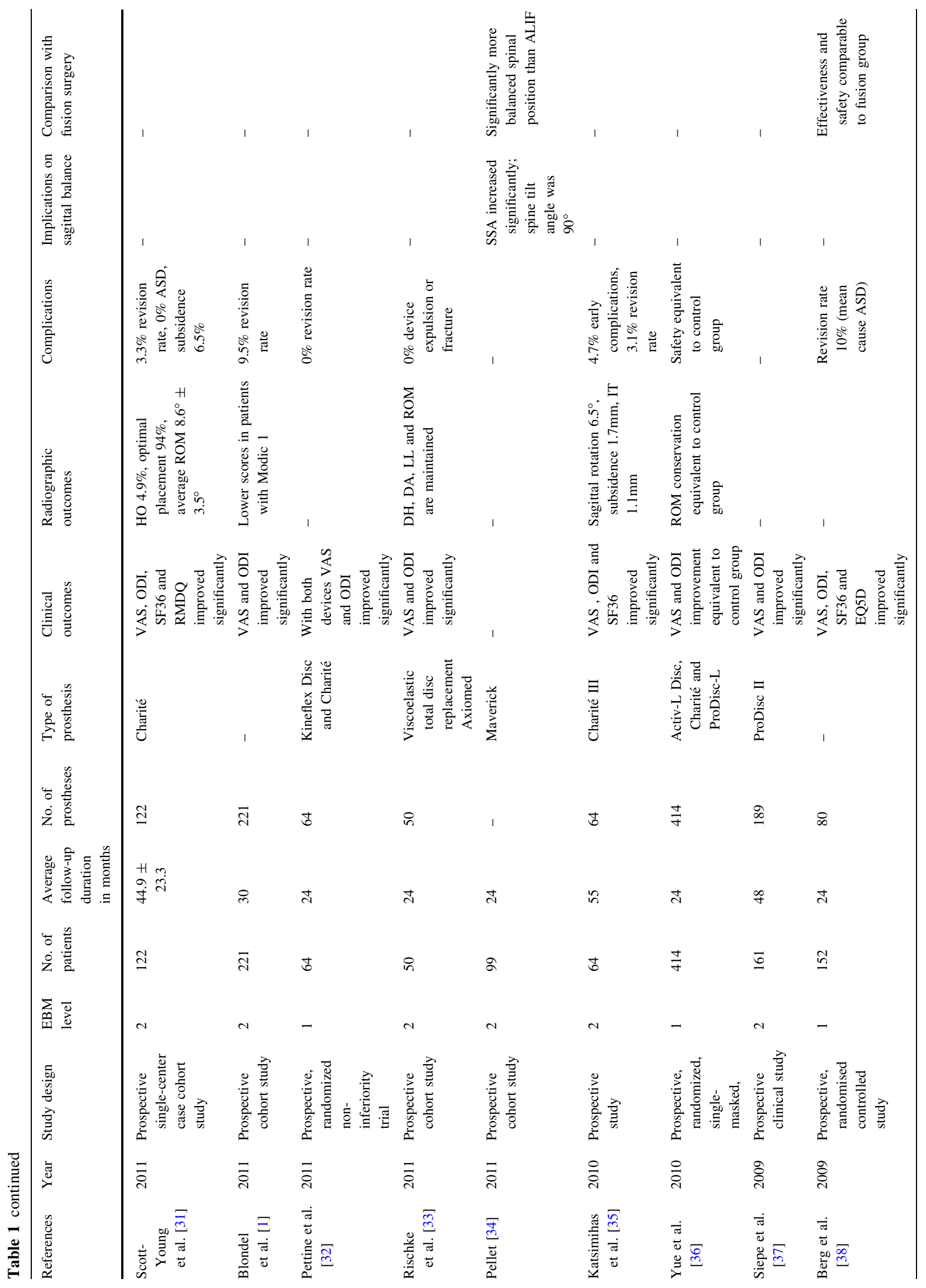




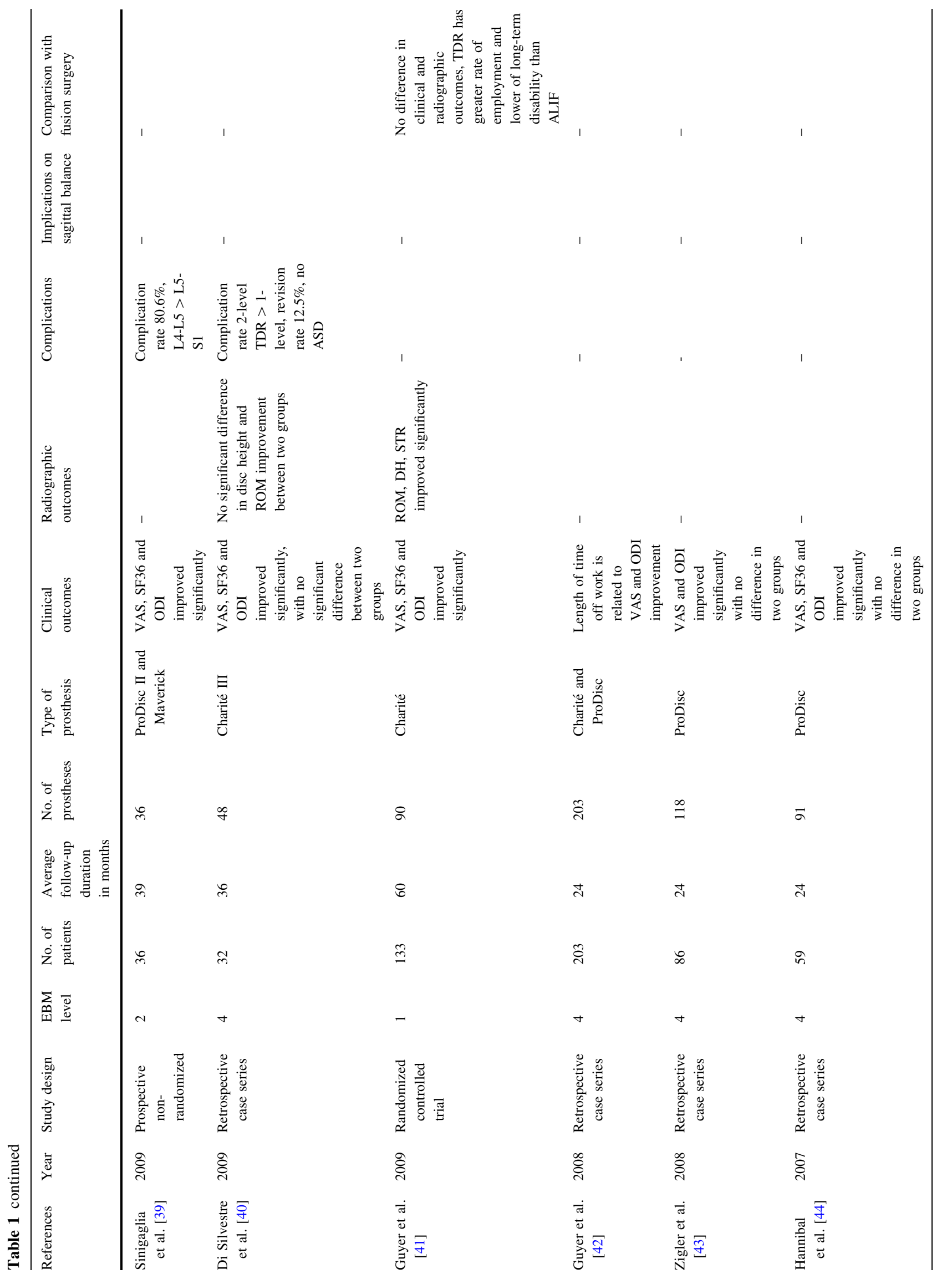




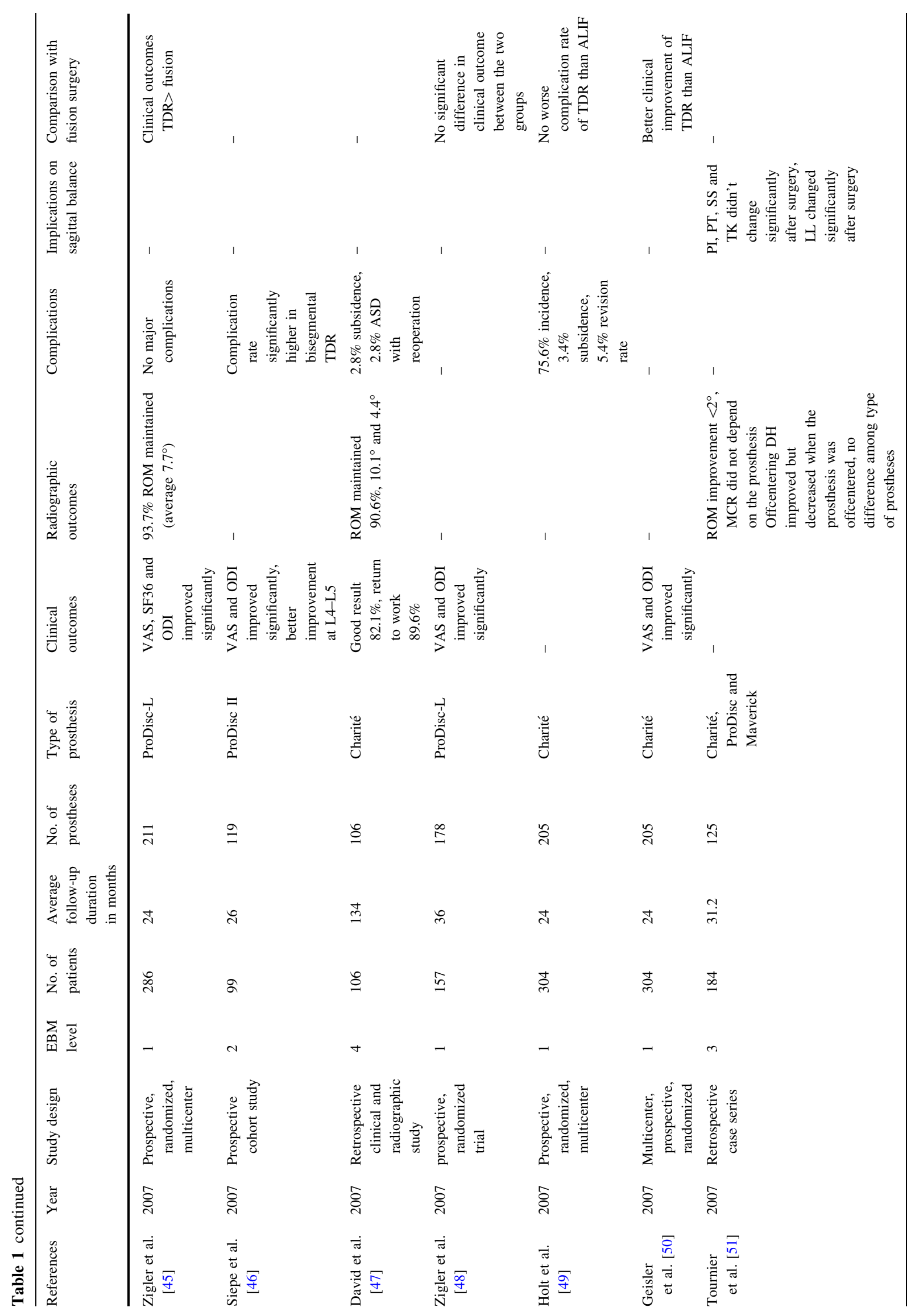




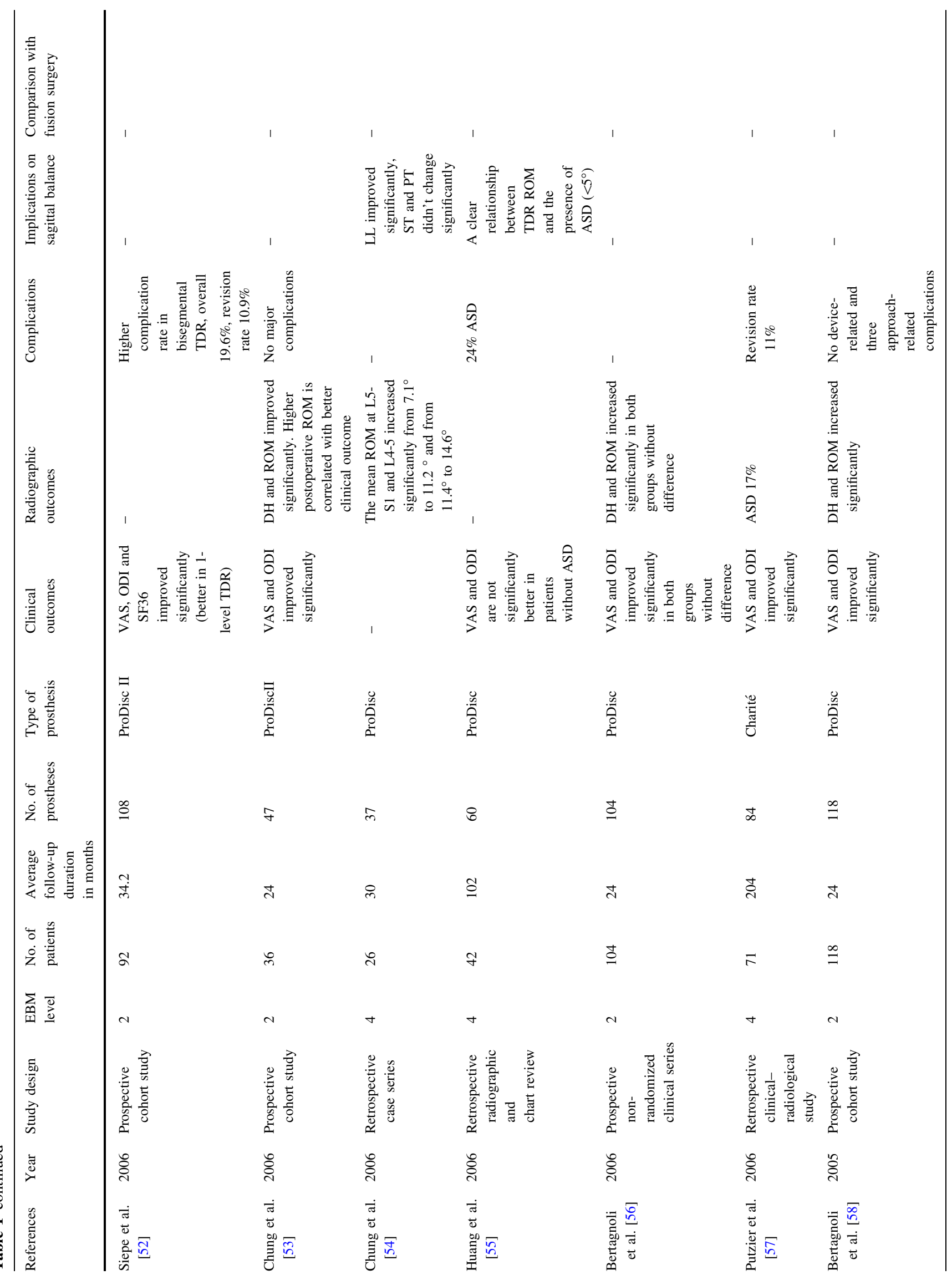


J Orthop Traumatol (2017) 18:197-215

207

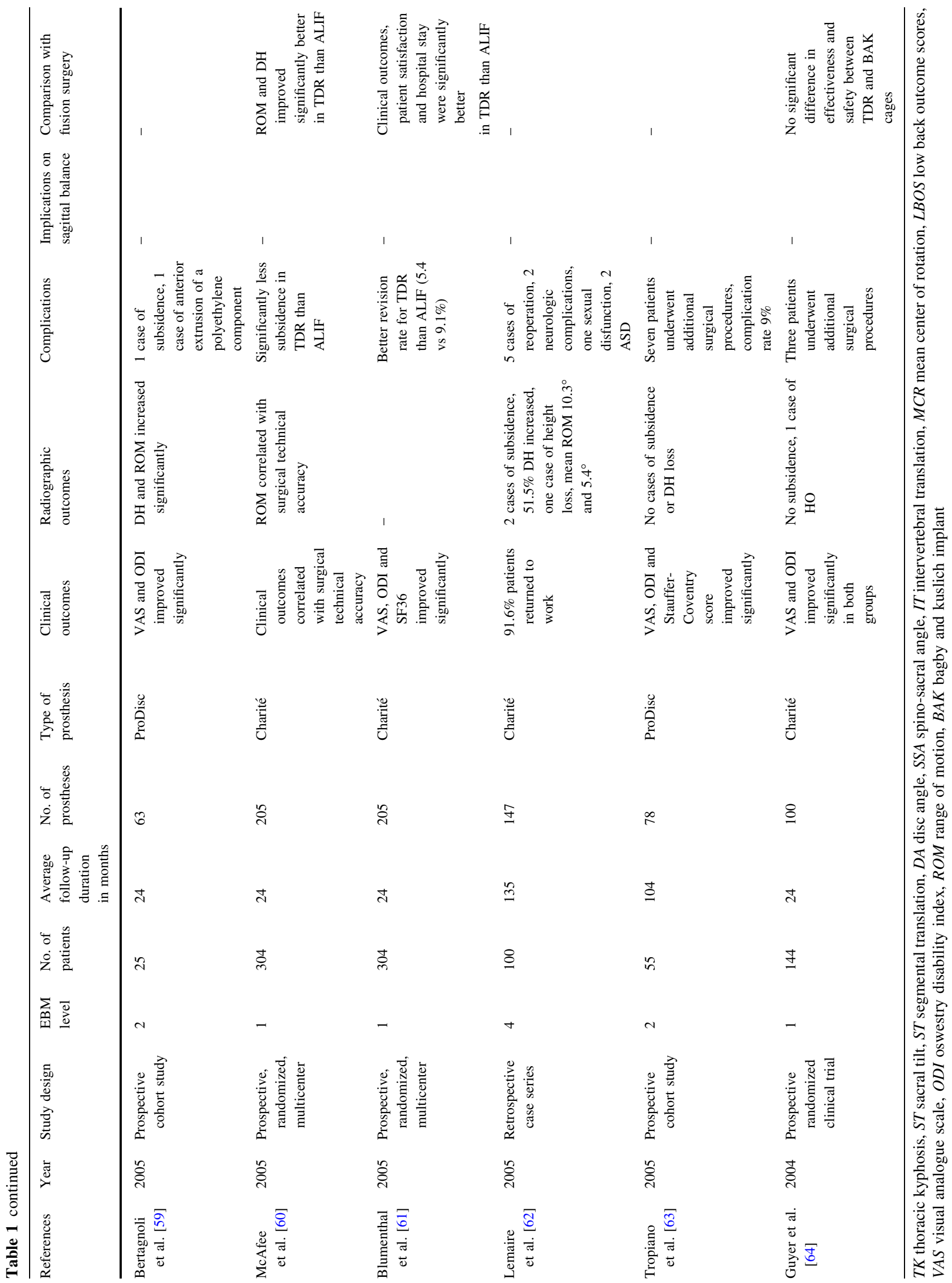

Springer 
This improvement lasts at all time points compared to baseline. The majority of the articles show there is no difference in terms of clinical outcome between the two groups.

Ziegler et al. [25] demonstrated that both TDR and fusion treatment groups obtain significant improvement in ODI at 5 years compared with baseline. VAS pain scores decreased from preoperative values by $48 \%$ in both treatment groups at 5 years. Patients were highly satisfied in both groups $(77 \%)$.

On the other hand, some articles underline a better clinical trend in the TDR group, although both surgical techniques lead to satisfying results. Skold et al. [22] conclude that significant differences in favour of TDR concerning back pain, pain improvement, and ODI were present at 1 year and disappeared at 2 years, but reappeared at the 5-year follow-up.

Trying to analyze functional outcomes, Guyer et al. [41] summarized that full-time employment was achieved by $65.6 \%$ of patients in the Charité, group versus $46.5 \%$ of patients in the BAK group.

Similarly, the rate of long-term disability (8 vs 20.9\%) achieved a statistically significant difference between groups. No significant difference was observed for all other parameters.

Oktenoglu et al. [23] showed that there was a statistically significant difference between the levels of blood loss in the two groups: the level of blood loss was significantly higher in the TDR group compared to the PTDS (posterior transpedicular dynamic stabilization) group. Furthermore, operation time and length of hospital stay were significantly longer in the TDR group compared to the posterior dynamic stabilization group.

Blumenthal et al. [61], by contrast, reported the hospital stay was significantly shorter in the Charite ${ }^{\mathrm{TM}}$ artificial disc group.

Another interesting aspect is the radiographical outcome in terms of spontaneous fusion, range of motion at the operated and adjacent level, postoperative disc height, rate of subsidence and spinopelvic parameters.

Ziegler et al. [25] reported that none of the TDRs developed spontaneous fusion. The segmental range of motion following TDR remained within normal range.

Oktenoglu et al. [23] showed comparable results in postoperative radiographic evaluation for both techniques (TDR and PTDS). Both dynamic systems provided spine stability.

McAfee et al. [60] noted that TDR patients had a $13.6 \%$ mean increase in mean flexion/extension ROM at 24 months postoperatively compared to baseline. The control group showed an $82.5 \%$ decrease in the same parameter. Besides, patients in the TDR group had significantly better restoration of disc height and less subsidence.

Berg et al. [30] found different results. The preoperative flexion-extension ROM was similar between the fusion and TDR groups, and preoperative disc heights of segments to be treated were between one and two standard deviations less than that previously established in a normative database. Seventy percent of fused patients had no mobility, whereas $85 \%$ of TDR patients were mobile at 24 months of follow-up. Moreover, they noticed significant differences at adjacent segments, with more translation and flexion-extension in the fusion group rather than in the TDR group.

Auerbach et al. [65] also analyzed the differences between TDR and fusion in terms of ROM. They found no preoperative differences at the L4/L5 or L5/S1 operative levels. At 24 months after surgery, within-group comparisons revealed a statistically significant increase in total lumbar ROM only in the group undergoing TDR at L4/5, while there were no significant differences within the groups undergoing fusions at L4/5, fusions at L5/S1, or TDR at L5/S1. Between-group comparisons revealed no significant differences. Segmental contribution to total lumbar ROM was significantly reduced at the operative level for fusions at both L4/5 and L5/S1. In the TDR group, segmental ROM at the operative level was reduced at L5/ $\mathrm{S} 1$ and relatively preserved when the operative level was L4/5. Segmental contribution to total lumbar ROM was significantly reduced at the operative level for fusions at both L4/5 and L5/S1. In the TDR group, segmental ROM at the operative level was reduced at L5/S1 and relatively preserved when the operative level was L4/5.

Fusion at L5/S1 was associated with a significant increase in segmental contribution to ROM at the first cranial adjacent level, with insignificant increases at each subsequent cranial adjacent level. The same was true for fusion at L4/L5 but this increase was not statistically significant. TDR at L4/5 was associated with small but significant increases in segmental ROM at the first cranial and caudal adjacent levels. TDR at L5/S1 did not result in a change in ROM at the first cranial adjacent level, but was associated with a significant increase in ROM at the second cranial adjacent level. TDR or fusion at whatever operative level did not result in significant changes in segmental ROM at cranial or caudal non-adjacent levels over the follow-up period.

Again, Oktenoglu et al. [23] reported that there were no significant differences observed between the preoperative and postoperative lumbar (LL) and segmental lordosis (SL) evaluations for both techniques.

Finally, Pellet et al. [34] evaluated TDR in terms of spinal balance. They observed that SSA (spinosacral angle) 
was considerably increased in the discal arthroplasty group, resulting in a significantly more balanced spinal position.

In the group of patients undergoing arthrodesis using the ALIF technique, no such significant improvement was found, despite the use of a lordotic cage.

They showed that in cases of low pelvic incidence, it was necessary to maintain a Roussouly type 1 or 2 back without increasing lordosis. Indeed, L4-L5 disc prostheses is a valuable approach in these subjects. L5-S1 arthrodesis seemed a more suitable approach for treating patients with elevated sacral slope (back type 3 or 4).

\section{What is the safety and rate of complications of total disc replacement surgery?}

The literature shows similar rates of complications between TDR and fusion procedures.

Lee et al. [12] noted that there was a trend toward more surgical-approach-related complications in the TDR group (16.7\%) compared to the TLIF group (5.0\%). The higher surgical-approach complication rate could be due to the steep learning curve of TDR surgery.

Holt et al. [49] observed no differences in terms of complication rate, also reporting a reoperation rate of 5.4\% in the TDR group and of $9.1 \%$ in the fusion group, which is a significant difference.

The same result was found by Guyer et al. [41], with additional index-level surgery performed in $7.7 \%$ of Charité patients and $16.3 \%$ of BAK patients.

Unfortunately is difficult to compare results because there are lots of confounding factors (e.g. type of prosthesis, sample size, epidemiological features, surgical experience). However, the main certainty seems to be that there are no significant differences, in terms of rate of complications and reoperation, between TDR and fusion techniques. In Table 2 we summarize rates and types of complications occurring in the examined papers.

\section{How does total disc replacement surgery influence sagittal balance?}

The implantation of a total disc arthroplasty can induce changes in spinal balance. Lazennec et al. [20] reported that only the SL significantly increased for about $10^{\circ}$ after implantation and remained stable afterward while variations in SS (sacral slope) and PT (pelvic tilt) were not significant. At the instrumented level, the mean center of rotation (MCR) location was physiological in $70 \%$ of mobile cases before surgery, $76 \%$ at 12 months, and $73 \%$ at 24 months and at the upper adjacent level in 89, 100, and $90 \%$ of cases, respectively. The average ROM in flexion/extension at 2-year follow-up was $5.4^{\circ}$ and $64.2^{\circ}$; $66 \%$ of cases were mobile at 12 months and $76 \%$ at
24 months. The ROM of the replaced disc and the adjacent upper level did not change significantly between different time points.

Huang et al. [55] underline a clear relationship between TDR ROM and the presence of ASD at 8.6-year follow-up: the patients with ASD had a ROM of $1.6^{\circ}$ and $61.3^{\circ}$ whereas the patients without ASD had ROM $4.7^{\circ}$ and $64.5^{\circ}$.

In fact, when patients were stratified by ROM, no patients with ROM $5^{\circ}$ or greater developed ASD. When patients were divided according to ROM $\left(5^{\circ}\right.$ or greater, and less than $5^{\circ}$ ), the prevalence of ASD was $0 \%$ in the high ROM group and $34 \%$ in the low ROM group. Similarly, in patients with ASD, $100 \%$ had ROM less than $5^{\circ}$. In patients without ASD, 59\% had ROM less than $5^{\circ}$.

In the study by Chung et al. [54] the mean sagittal ROM at each operative segment increased significantly from $7.1^{\circ}$ to $11.2^{\circ}$ and from $11.4^{\circ}$ to $14.6^{\circ}$ at the L5-S1 and L4-5 levels, respectively.

In all patients who underwent a single- or double-level TDR, the mean LL and SL at L4-5 level increased significantly, while an analysis of the changes in the ST (sacral tilt), PT and SL at L1-2, L2-3, L3-4, and L5-S1 levels did not show significant differences.

Among patients who underwent a single-level TDR at the L4-5 level, the mean SL at the L4-5 operative level and the mean LL increased significantly and there was no significant difference in the ST, PT, and the SL at the L1-2, L2-3, L3-4, and L5-S1 levels.

In patients who underwent a single-level TDR at the L5S1 level, the mean SL at the L5-S1 level increased significantly. The LL showed a similar trend to that of the single-level TDR at the L4-5 level, but there was no statistical significance.

No significant difference was detected for the ST, PT, and the SL at the L1-2, L2-3, L3-4, and L4-5 levels.

Le Huec et al. [66] reported that the changes in global lordosis, SS, and PT were not significant in patients undergoing a single-level TDR. Additionally, there was no significant difference in the preoperative and postoperative values of kyphosis, segmental lordosis of L4-L5, or L5$\mathrm{S} 1$. There was no statistical difference with regard to the overall lordosis, SS, PT, or kyphosis when the two groups were compared with each other.

However, if we consider only the L4-L5 group, the segmental lordosis was significantly increased after the total disc arthroplasty. The same results were obtained in the L5-S1 group. While the prosthesis increased lordosis at the level implanted, the overall lordosis did not change, thus indicating the adaptability of the spine as a whole to maintain lordosis. Furthermore, an angular change of more than $3^{\circ}$ was observed in all patients with average motion of $6.5^{\circ}\left(7.3^{\circ}\right.$ and $5.2^{\circ}$ at L4-L5 and L5-S1, respectively). 


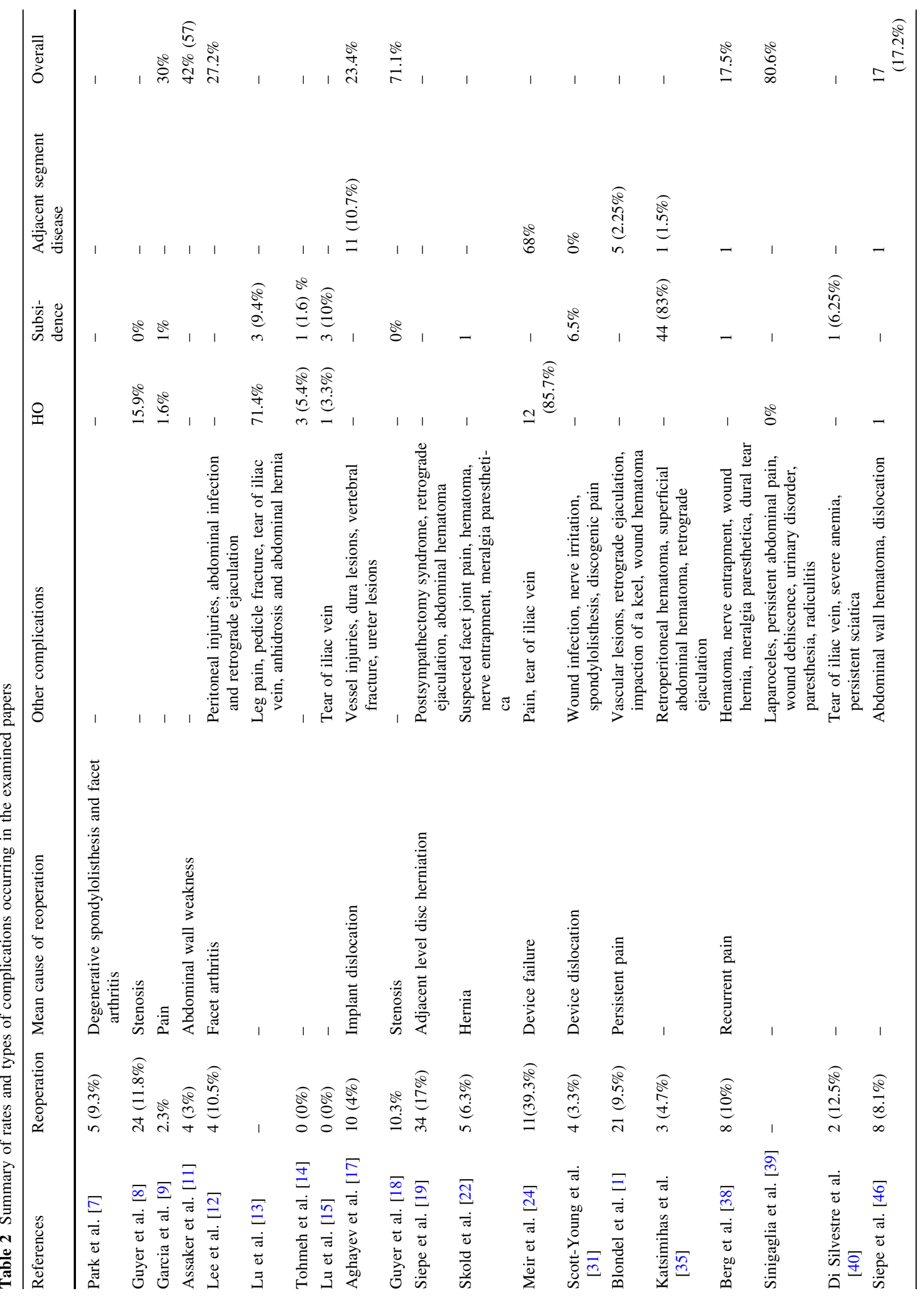


J Orthop Traumatol (2017) 18:197-215

211

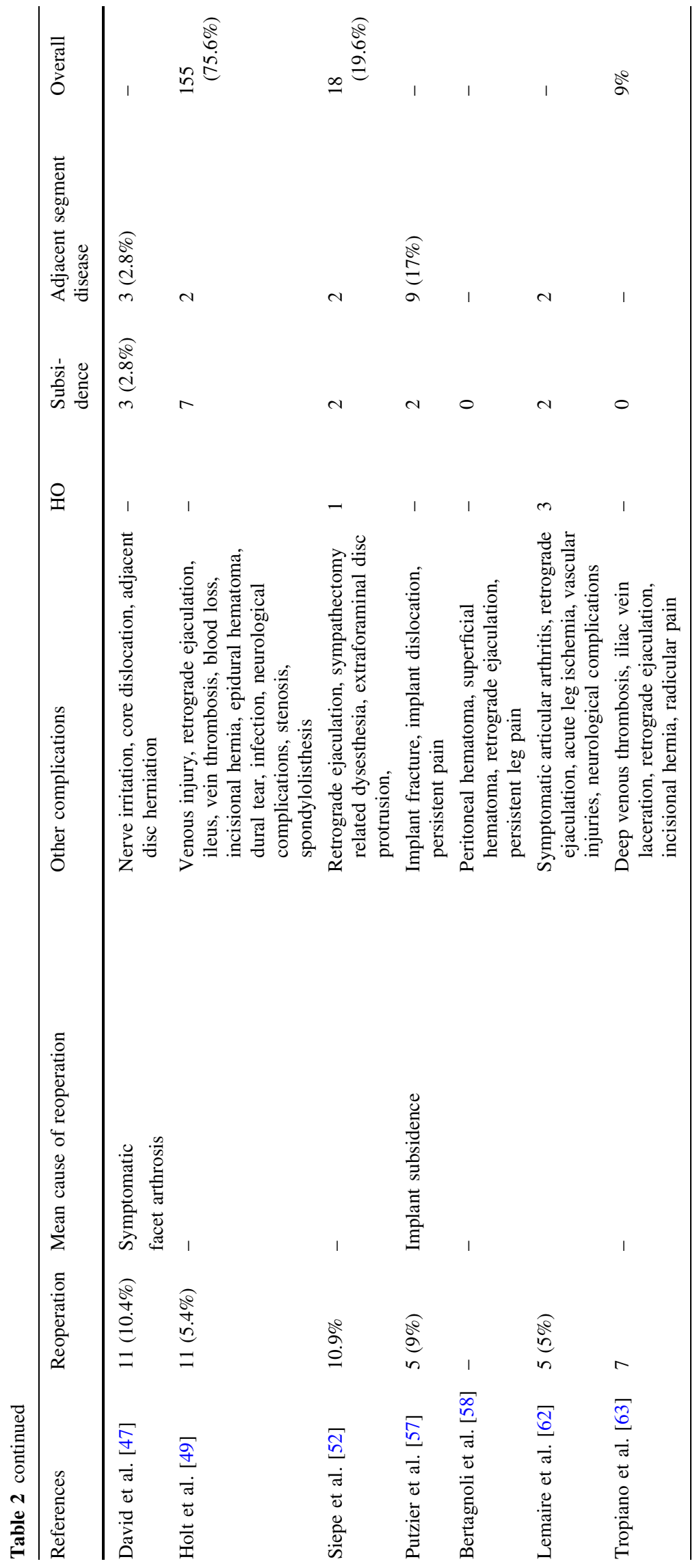

Springer 
Pellet et al. [34] made an important contribution to this topic. They reported that the spinosacral angle (SSA) increases significantly after disc arthroplasty, resulting in a more balanced spinal position. The C7 plumb line shifted behind the posterior superior corner of $\mathrm{S} 1$ and became negative in the majority of patients. The authors observed a significant increase in SSA among patients undergoing L5S1 arthroplasty, as well as backward displacement of the C7 plumb line. In the L4-L5 group there was a non-statistically significant increase in SSA, while the postoperative plumb line had moved behind the posterior superior angle at $\mathrm{S} 1$.

This paper underlines a clear difference in the 4 back types (according to Roussouly's classification) in terms of spinopelvic parameters (pelvic incidence PI, PT, SS and SSA) but not of balance parameters (S1-C7, hip axis and S1 vertebra and C7 ratio). The difference in terms of SSA found preoperatively between the different back types was not seen postoperatively. The SSA was highly correlated with PI, SS and distal LL; it was negatively correlated with the $\mathrm{C} 7$ plumb line.

Finally, Tournier et al. [51] explored every spinopelvic parameter separately. The mean PI is not different before and after disc replacement. The same happens for pelvic tilt: only $89 \%$ of the patients were in the normal range. The authors found an improvement only after L5-S1 prosthesis. Nearly $92 \%$ of the patients had a normal SS before surgery, 94.2\% after TDR. The mean SS improves after L5-S1 prosthesis (from $35.4^{\circ}$ to $36.3^{\circ}$ ) and L4-L5 prosthesis (from $36.2^{\circ}$ to $37.4^{\circ}$ ).

The mean lumbar lordosis in the total sample is significantly higher after total disc replacement. The increase of L1-S1 lordosis is neither linked with an increased angle at the prosthesis level, nor with an increased ROM at the prosthesis level. Almost $94 \%$ of the patients have a postoperative LL in the physiological range. The L1-S1 lordosis is associated neither with the sagittal prosthesis centring, nor with prosthesis size. The lumbar curvature depends on the prosthesis level: L4-S1 curvature represents $93 \%$ of the total LL after L3-L4 prosthesis, and $73 \%$ of the total LL after L4-L5 and L5-S1 prostheses. The mean thoracic kyphosis (T4-T12) is $37^{\circ}$ before surgery and $36.7^{\circ}$ after total disc arthroplasty. The difference is not significant.

\section{Discussion}

Lumbar fusion, including traditional techniques with different approaches, is a well-established surgical technique for the treatment of degenerative disc diseases [67, 68].

Even if clinical outcomes are satisfactory and lead to well-known benefits, the original biomechanics of the spine is altered because of the lack of motion at the fused segments. In addition, spinal fusion is burdened by a not negligible rate of adjacent segment degeneration. TDR has increased in popularity as an alternative for lumbar fusion. The technique aims to restore and maintain spinal segment motion, attempting to prevent adjacent level degeneration at upper or lower segments.

Certainly, there is still debate on the preferred surgical technique, because TDR cannot be considered a complication-free procedure. Moreover, the increasing attention given to spinal balance allows the evaluation of TDR according to this new perspective. The main focus for establishing the ideal surgical technique is clinical outcome.

Most papers show significant effectiveness of TDR in terms of improvement in all clinical scores. Along with clinical aspects, blood loss, hospital stay, length of surgery and medication use have been evaluated. TDR shows significant superiority in shortened duration of hospitalization when compared to fusion techniques. There was no significant difference in operation time, blood loss, complications, reoperation rate and proportion of patients who returned to full-time/part-time work between the TDR group and the fusion group. Of course, different fusion procedures and different types of artificial discs may represent biases in comparing outcomes. In addition, the results are affected by heterogeneity caused by random sampling and different epidemiological features.

In most of the included articles, there is no clear and general consensus about the indications of these two surgical procedures. However, it is well known that fusion surgery indications are wider than TDR ones. Anyway, especially for young patients suffering from DDD without any significant instability, deformity or osteoporosis, TDR might be a suitable alternative to lumbar fusion.

In terms of safety, TDR shows some differences in comparison to fusion techniques. While there are no significant differences in overall rate of complications or reoperation, there is some diversity when we analyze the types of complications.

It is universally accepted that the main limits of the fusion technique are loss of motion at the operative level, and adjacent segment degeneration.

There is moderate evidence to suggest that patients who undergo fusion may be nearly 6 times more likely to be treated for ASD than those who undergo TDR. From 2 randomized trials, the pooled risk of clinical ASD treated surgically was 1.2 and $7.0 \%$ in the TDR and fusion groups, respectively [69].

While TDR restores spinal segment motion, it is burdened by the same kinds of complications that affect an anterior approach to the spine. That's why we are not surprised to find a higher rate of access-related complications in comparison to fusion surgery, with a not negligible number of great vessel injuries, abdominal wall lesions and 
retrograde ejaculation. The rate of surgical-approach-related complications in the ADR group was $16.7 \%$, while that in the TLIF group was $5.0 \%$. Complications included peritoneal injuries $(n=5 ; 9.3 \%)$, superficial abdominal infection $(n=3 ; 5.6 \%)$ and retrograde ejaculation $(n=1$; $1.9 \%)$ [12].

The major advantages of a lumbar TDR over fusion include the maintenance of segmental motion and the restoration of the disc height. These two features became fundamental when we correlate TDR outcomes according a spinal balance evaluation.

Sagittal balance has to be considered in every spinal surgical procedure. Surgical correction of this parameter, especially when heavily impaired, is mandatory and often affected by severe complications due to the complexity of the procedure itself [70].

Most of the analyzed papers show that the variables in the patient population with degenerative disc disease are similar to those of asymptomatic individuals. However, several surgical treatments, including spinal fusions, can deleteriously alter the sagittal balance.

The tendency towards normalization of the alterations of sagittal balance, or at least maintaining it, confirmed the regulatory role of total disc arthroplasty, which allows patients to position themselves appropriately. This motion preserving technique refurbishes the compensatory mechanisms at the operated segment, allowing patients to find their own spinal balance. In order to achieve these goals, the correct positioning of the prosthesis in terms of size and mean center of rotation is of paramount importance.

In conclusion, although further studies with larger groups of patients and a longer follow-up period is needed to better evaluate the outcomes and safety of lumbar TDR, it seems clear that disc arthroplasty could be a reliable option in the treatment of degenerative disc disease in years to come.

\section{Compliance with ethical standards}

Conflict of interest The authors have no conflicts of interest to disclose.

Patient consent Not applicable, as the study does not involve any human subjects.

Ethical approval Not applicable, as the study does not involve any human or animal subjects.

\section{Funding None.}

Open Access This article is distributed under the terms of the Creative Commons Attribution 4.0 International License (http://crea tivecommons.org/licenses/by/4.0/), which permits unrestricted use, distribution, and reproduction in any medium, provided you give appropriate credit to the original author(s) and the source, provide a link to the Creative Commons license, and indicate if changes were made.

\section{References}

1. Blondel B, Tropiano P, Gaudart J, Huang RC, Marnay T (2011) Clinical results of lumbar total disc arthroplasty in accordance with Modic signs, with a 2-year-minimum follow-up. Spine 36(26):2309-2315. doi:10.1097/BRS.0b013e31820f7372

2. Cavagnaro L, Basso M, Mazzola MA, Formica M (2014) Lumbar traction in the management of low back pain: a survey of latest results. J Nov Physiother 4:231. doi:10.4172/2165-7025.1000231

3. Formica M, Cavagnaro L, Formica C, Mastrogiacomo M, Basso M, Di Martino A (2015) What is the preclinical evidence on platelet rich plasma and intervertebral disc degeneration? Eur Spine J 24(11):2377-2386. doi:10.1007/s00586-015-4189-2 (Epub 2015 Aug 14)

4. Parkinson B, Goodall S, Thavaneswaran P (2013) Cost-effectiveness of lumbar artificial intervertebral disc replacement: driven by the choice of comparator. ANZ J Surg 83(9):669-675. doi:10.1111/ans.12009 (Epub 2012 Nov 29)

5. Turner JA, Ersek M, Herron L, Haselkorn J, Kent D, Ciol MA, Deyo R (1992) Patient outcomes after lumbar spinal fusions. JAMA 268(7):907-911. doi:10.1001/jama.1992. 03490070089049

6. Frelinghuysen P, Huang RC, Girardi FP, Cammisa FP Jr (2005) Lumbar total disc replacement part I: rationale, biomechanics, and implant types. Orthop Clin North Am 36(3):293-299. doi:10. 1016/j.ocl.2005.02.014

7. Park S-J, Lee C-S, Chung S-S, Lee K-H, Kim W-S, Lee J-Y (2016) Long-term outcomes following lumbar total disc replacement using ProDisc-II. Spine 41(21):971-977. doi:10. 1097/BRS.0000000000001527

8. Guyer RD, Pettine K, Roh JS, Dimmig TA, Coric D, McAfee PC, Ohnmeiss DD (2016) Five-year follow-up of a prospective, randomized trial comparing two lumbar total disc replacements. Spine 41(1):3-8. doi:10.1097/BRS.0000000000001168

9. Jr RG, Yue JJ, Blumenthal S, Coric D, Patel VV, Leary SP, Dinh DH, Buttermann GR, Deutsch H, Girardi F, Billys J, Miller LE (2015) Lumbar total disc replacement for discogenic low back pain: two-year outcomes of the activL multicenter randomized controlled IDE clinical trial. Spine 40:1873-1881. doi:10.1097/ BRS.0000000000001245

10. Schätz C, Ritter-Lang K, Gössel L, Dreßler N (2015) Comparison of single-level and multiple-level outcomes of total disc arthroplasty: 24-month results. Int J Spine Surg 9:14. doi:10.14444/ 2014

11. Assaker R, Ritter-Lang K, Vardon D, Litrico S, Fuentes S, Putzier M, Franke J, Jarzem P, Guigui P, Nakach G, Le Huec J-C (2015) Maverick total disc replacement in a real-world patient population: a prospective, multicentre, observational study. Eur Spine J 24:2047-2055. doi:10.1007/s00586-015-3918-x

12. Lee WT, Liu G, Thambiah J, Wong HK (2015) Clinical outcomes of single-level lumbar artificial disc replacement compared with transforaminal lumbar interbody fusion in an Asian population. Singap Med J 56(4):208-211. doi:10.11622/smedj.2015032

13. Lu S-B, Hai Y, Kong C, Wang Q-Y, Su Q, Zang L, Kang N, Meng X-L, Wang Y (2015) An 11-year minimum follow-up of the Charite III lumbar disc replacement for the treatment of symptomatic degenerative disc disease. Eur Spine J 24:2056-2064. doi:10.1007/s00586-015-3939-5

14. Tohmeh AG, Smith WD (2015) Lumbar total disc replacement by less invasive lateral approach: a report of results from two centers in the US IDE clinical trial of the XL TDR device. Eur Spine J 24:S331-S338. doi:10.1007/s00586-015-3843-Z

15. Lu S, Kong C, Hai Y, Wang Q, Zang L, Kang N, Meng X, Wang Y (2015) Retrospective study on effectiveness of activL total disc 
replacement. Spine 40(7):411-417. doi:10.1097/BRS. 0000000000000773

16. Trincat S, Edgard-Rosa G, Geneste G, Marnay T (2015) Twolevel lumbar total disc replacement: functional outcomes and segmental motion after 4 years. Orthop Traumatol Surg Res 101:17-21. doi:10.1016/j.otsr.2014.10.014

17. Aghayev E, Etter C, Barlocher C, Sgier F, Otten P, Heini P, Hausmann O, Maestretti G, Baur M, Baur M, Porchet F, Markwalder TM, Scharen S, Neukamp M, Roder C (2014) Five-year results of lumbar disc prostheses in the SWISSspine registry. Eur Spine J 23:2114-2126. doi:10.1007/s00586-014-3418-4

18. Guyer RD, Pettine K, Roh JS, Dimmig TA, Coric D, McAfee PC, Ohnmeiss DD (2014) Comparison of 2 lumbar total disc replacements, results of a prospective, randomized, controlled, multicenter food and drug administration trial with 24-month follow-up. Spine 39(12):925-931. doi:10.1097/BRS.0000000000000319

19. Siepe CJ, Heider F, Wiechert K, Hitzl W, Ishak B, Mayer MH (2014) Mid- to long-term results of total lumbar disc replacement: a prospective analysis with 5- to 10-year follow-up. Spine J 14:1417-1431

20. Lazennec J-Y, Even J, Skalli W, Rakover J-P, Brussona A, Rousseau M-A (2014) Clinical outcomes, radiologic kinematics, and effects on sagittal balance of the 6 df LP-ESP lumbar disc prosthesis. Spine J 14:1914-1920

21. Strube P, Hoff EK, Schmidt H, Dreischarf M, Rohlmann A, Putzier M (2013) Parameters influencing the outcome after total disc replacement at the lumbosacral junction. Part 2: Distraction and posterior translation lead to clinical failure after a mean follow-up of 5 years. Eur Spine J 22:2279-2287. doi:10.1007/ s00586-013-2967-2

22. Skold C, Tropp H, Berg S (2013) Five-year follow-up of total disc replacement compared to fusion: a randomized controlled trial. Eur Spine J 22:2288-2295. doi:10.1007/s00586-013-2926-y

23. Oktenoglu T, Ozer AF, Sasani M, Ataker Y, Gomleksiz C, Celebi I (2013) Posterior transpedicular dynamic stabilization versus total disc replacement in the treatment of lumbar painful degenerative disc disease: a comparison of clinical results. Adv Orthop 2013:9. doi:10.1155/2013/874090

24. Meir AR, Freeman BJC, Fraser RD, Fowler SM (2013) Ten-year survival and clinical outcome of the AcroFlex lumbar disc replacement for the treatment of symptomatic disc degeneration. Spine J 13(2013):13-21. doi:10.1016/j.spinee.2012.12.008

25. Zigler JE, Delamarter RB (2012) Five-year results of the prospective, randomized, multicenter, Food and Drug Administration investigational device exemption study of the ProDisc-L total disc replacement versus circumferential arthrodesis for the treatment of single-level degenerative disc disease. J Neurosurg Spine 17:493-501. doi:10.3171/2012.9.SPINE11498

26. Jones CW, Smitham P, Walsh WR (2012) Relationship of surgical accuracy and clinical outcomes in Charitélumbar disc replacement. Orthop Surg 4:145-155. doi:10.1111/j.1757-7861. 2012.00191.x

27. Siepe CJ, Heider F, Haas E, Hitzl W, Szeimies U, Stabler A, Weiler C, Nerlich AG, Mayer MH (2012) Influence of lumbar intervertebral disc degeneration on the outcome of total lumbar disc replacement: a prospective clinical, histological, X-ray and MRI investigation. Eur Spine J 2012(21):2287-2299. doi:10. 1007/s00586-012-2342-8

28. Van de Kelft E, Verguts L (2012) Clinical outcome of monosegmental total disc replacement for lumbar disc disease with ball-and-socket prosthesis (Maverick): prospective study with four-year follow-up. World Neurosurg 78(3/4):355-363. doi:10.1016/j.wneu.2011.10.043

29. Park C-K, Ryu K-S, Lee K-Y, Lee H-J (2012) Clinical outcome of lumbar total disc replacement using ProDisc-L in degenerative disc disease minimum 5-year follow-up results at a single institute. Spine 37(8):672-677. doi:10.1097/BRS.0b013e31822ecd85

30. Berg S, Tropp HT, Leivseth G (2011) Disc height and motion patterns in the lumbar spine in patients operated with total disc replacement or fusion for discogenic back pain. Results from a randomized controlled trial. Spine J 11(2011):991-998. doi:10. 1016/j.spinee.2011.08.434

31. Scott-Young MN, Lee MJ, Nielsen DEA, Magno CL, Kimlin KR, Mitchell EO (2011) Clinical and radiological mid-term outcomes of lumbar single-level total disc replacement. Spine. doi:10.1097/ BRS.0b013e3182345aa2

32. Pettine K, Hersh A (2011) Kineflex lumbar artificial disc versus Charité lumbar total disc replacement for the treatment of degenerative disc disease: a randomized non-inferiority trial with minimum of 2 years' follow-up. SAS J 5(2011):108-113. doi:10. 1016/j.esas.2011.07.003

33. Rischke B, Ross RS, Jollenbeck BA, Zimmers KB, Defibaugh ND (2011) Preclinical and clinical experience with a viscoelastic total disc replacement. SAS J 5(2011):97-107. doi:10.1016/j. esas.2011.08.001

34. Pellet N, Aunoble S, Meyrat R, Rigal J, Le Huec JC (2011) Sagittal balance parameters influence indications for lumbar disc arthroplasty or ALIF. Eur Spine J 20(Suppl 5):S647-S662. doi:10.1007/s00586-011-1933-0

35. Katsimihas M, Bailey CS, Issa K, Fleming J, Rosas-Arellano P, Bailey SI, Gurr KR (2011) Prospective clinical and radiographic results of CHARITÉ III artificial total disc arthroplasty at 2- to 7-year follow-up: a Canadian experience. J can chir 53(6):408

36. Yue JJ, Mo FF (2010) Clinical study to evaluate the safety and effectiveness of the Aesculap Activ- $\mathrm{L}^{\mathrm{TM}}$ artificial disc in the treatment of degenerative disc disease. BMC Surg 2010(10):14. doi:10.1186/1471-2482-10-14

37. Siepe CJ, Tepass A, Hitzl W, Meschede P, Beisse R, Korge A, Michael Mayer H (2009) Dynamics of improvement following total lumbar disc replacement: is the outcome predictable? Spine 34(23):2579-2586

38. Berg S, Tullberg T, Branth B, Olerud C, Tropp H (2009) Total disc replacement compared to lumbar fusion: a randomized controlled trial with 2-year follow-up. Eur Spine J 18:1512-1519. doi:10.1007/s00586-009-1047-0

39. Sinigaglia R, Bundy A, Costantini S, Nena U, Finocchiaro F, Monterumici DAF (2009) Comparison of single-level L4-L5 versus L5-S1 lumbar disc replacement: results and prognostic factors. Eur Spine J 18(Suppl 1):S52-S63. doi:10.1007/s00586009-0992-y

40. Di Silvestre M, Bakaloudis G, Lolli F, Vommaro F, Parisini P (2009) Two-level total lumbar disc replacement. Eur Spine J 18(Suppl 1):S64-S70. doi:10.1007/s00586-009-0982-0

41. Guyer RD, McAfee PC, Banco J, Bitan FD, Cappuccino A, Geisler FH, Hochschuler SH, Holt RT, Jenis LG, Majd ME, Regan JJ, Tromanhauser SG, Wong DC, Blumenthal SL (2009) Prospective, randomized, multicenter Food and Drug Administration investigational device exemption study of lumbar total disc replacement with the CHARITE artificial disc versus lumbar fusion: five-year follow-up. Spine J 9(2009):374-386. doi:10. 1016/j.spinee.2008.08.007

42. Guyer RD, Siddiqui S, Zigler JE, Ohnmeiss DD, Blumenthal SL, Sachs BL, Hochschuler SH, Rashbaum RF (2008) Lumbar spinal arthroplasty analysis of one center's twenty best and twenty worst clinical outcomes. Spine 33(23):2566-2569

43. Zigler JE, Ohnmeiss DD (2008) Comparison of 2-level versus 1-level total disc replacement: results from a prospective FDAregulated trial. SAS J 2008(2):140-144

44. Hannibal M, Thomas DJ, Low J, Hsu KY, Zucherman J (2007) ProDisc-L total disc replacement. A comparison of 1-level versus 
2-level arthroplasty patients with a minimum 2-year follow-up. Spine 32(21):2322-2326

45. Zigler J, Delamarter R, Spivak JM, Linovitz RJ, Danielson GO, Haider TT, Cammisa F, Zuchermann J, Balderston R, Kitchel S, Foley K, Watkins R, Bradford D, Yue J, Yuan H, Herkowitz H, Geiger D, Bendo J, Peppers T, Sachs B, Girardi F, Kropf M, Goldstein J (2007) Results of the prospective, randomized, multicenter Food and Drug Administration investigational device exemption study of the ProDisc-L total disc replacement versus circumferential fusion for the treatment of 1-level degenerative disc disease. Spine 32(11):1155-1162

46. Siepe CJ, Mayer HM, Heinz-Leisenheimer M, Korge A (2007) Total lumbar disc replacement: different results for different levels. Spine 32(7):782-790

47. David T (2007) Long-term results of one-level lumbar arthroplasty minimum 10-year follow-up of the CHARITÉ artificial disc in 106 patients. Spine 32(6):661-666

48. Zigler JE, Sachs BL, Rashbaum RF, Ohnmeiss DD (2007) Twoto 3-year follow-up of Prodisc-1: results from a prospective randomized trial of arthroplasty versus fusion. SAS J 2007(1):63-67

49. Holt RT, Majd ME, Isaza JE, Blumenthal SL, McAfee PC, Guyer RD, Hochschuler SH, Geisler FH, Jr RGarcia, Regan JJ (2007) Complications of lumbar artificial disc replacement compared to fusion: results from the prospective, randomized, multicenter US Food and Drug Administration investigational device exemption study of the Charite artificial disc. SAS J 2007(1):20-27

50. Geisler HF (2007) Surgical treatment for discogenic low-back pain: lumbar arthroplasty results in superior pain reduction and disability level improvement compared with lumbar fusion. SAS J 1:12-19

51. Tournier C, Aunoble S, Le Huec JC, Lemaire JP, Tropiano P, Lafage V, Skalli W (2007) Total disc arthroplasty: consequences for sagittal balance and lumbar spine movement. Eur Spine $\mathrm{J}$ 2007(16):411-421. doi:10.1007/s00586-006-0208-7

52. Siepe CJ, Michael Mayer H, Wiechert K, Korge A (2006) Clinical results of total lumbar disc replacement with ProDisc II three-year results for different indications. Spine 31(17): 1923-1932

53. Chung SS, Lee CS, Kang CS (2006) Lumbar total disc replacement using ProDisc II, a prospective study with a 2-year minimum follow-up. J Spinal Disord Tech 19:411-415

54. Chung SS, Lee CS, Kang CS, Kim SH (2006) The effect of lumbar total disc replacement on the spinopelvic alignment and range of motion of the lumbar spine. J Spinal Disord Tech 19:307-311

55. Huang RC, Tropiano P, Marnay T, Girardi FP, Lim MR, Cammisa FP Jr (2006) Range of motion and adjacent level degeneration after lumbar total disc replacement. Spine J 6(2006):242-247. doi:10.1016/j.spinee.2005.04.013

56. Bertagnoli R, Yue JJ, Kershaw T, Shah RV, Pfeiffer F, FenkMayer A, Nanieva R, Karg A, Husted DS, Emerson JW (2006) Lumbar total disc arthroplasty utilizing the Prodisc prosthesis in smokers versus nonsmokers a prospective study with 2-year minimum follow-up. Spine 31(9):992-997

57. Putzier M, Funk JF, Schneider SV, Gross C, Tohtz SW, Khodadadyan-Klostermann C, Perka C, Kandziora F (2006) Charité total disc replacement-clinical and radiographical results after an average follow-up of 17 years. Eur Spine J 15:183-195. doi:10.1007/s00586-005-1022-3

58. Bertagnoli R, Yue JJ, Shah RV, Nanieva R, Pfeiffer F, FenkMayer A, Kershaw T, Husted DS (2005) The treatment of disabling single-level lumbar discogenic low back pain with total disc arthroplasty utilizing the prodisc prosthesis. A prospective study with 2-year minimum follow-up. Spine 30(19):2230-2236

59. Bertagnoli R, Yue JJ, Shah RV, Nanieva R, Pfeiffer F, FenkMayer A, Kershaw T, Husted DS (2005) The treatment of disabling multilevel lumbar discogenic low back pain with total disc arthroplasty utilizing the Prodisc prosthesis. A prospective study with 2-year minimum follow-up. Spine 30(19):2192-2199

60. McAfee PC, Cunningham B, Holsapple G, Adams K, Blumenthal S, Guyer RD, Dmietriev A, Maxwell JH, Regan JJ, Isaza J (2005) A prospective, randomized, multicenter Food and Drug Administration investigational device exemption study of lumbar total disc replacement with the CHARITÉ ${ }^{\mathrm{TM}}$ artificial disc versus lumbar fusion. Part II: Evaluation of radiographic outcomes and correlation of surgical technique accuracy with clinical outcomes. Spine 30(14):1576-1583

61. Blumenthal S, McAfee PC, Guyer RD, Hochschuler SH, Geisler FH, Holt RT, Garcia R Jr, Regan JJ, Ohnmeiss DD (2005) A prospective, randomized, multicenter Food and Drug Administration investigational device exemptions study of lumbar total disc replacement with the CHARITÉ ${ }^{\mathrm{TM}}$ artificial disc versus lumbar fusion. Part I: evaluation of clinical outcomes. Spine 30(14):1565-1575

62. Lemaire J-P, Carrier H, Ali E-HS, Skalli W, Lavaste F (2005) Clinical and radiological outcomes with the Charite ${ }^{\mathrm{TM}}$ artificial disc. A 10-year minimum follow-up. J Spinal Disord Tech 18:353-359

63. Tropiano P, Huang RC, Girardi FP, Cammisa FP Jr, Marnay T (2005) Lumbar total disc replacement seven to eleven-year follow-up. J Bone Joint Surg. doi:10.2106/jbjs.c.01345

64. Guyer RD, McAfee PC, Hochschuler SH, Blumenthal SL, Fedder IL, Ohnmeiss DD, Cunningham BW (2004) Prospective randomized study of the Charite artificial disc: data from two investigational centers. Spine J 4(2004):252S-259S. doi:10.1016/ j.spinee.2004.07.019

65. Auerbach JD, Jones KJ, Milby AH, Anakwenze OA, Balderston RA (2009) Segmental contribution toward total lumbar range of motion in disc replacement and fusions. A comparison of operative and adjacent levels. Spine 34(23):2510-2517

66. Le Huec JC, Basso Y, Mathews H, Mehbod A, Aunoble S, Friesem T, Zdeblick T (2005) The effect of single-level, total disc arthroplasty on sagittal balance parameters: a prospective study. Eur Spine J 14:480-486. doi:10.1007/s00586-004-0843-9

67. Formica M, Berjano P, Cavagnaro L, Zanirato A, Piazzolla A, Formica C (2014) Extreme lateral approach to the spine in degenerative and post traumatic lumbar diseases: selection process, results and complications. Eur Spine J 23(Suppl 6):684-692. doi:10.1007/s00586-014-3545-y (Epub 2014 Sep 12)

68. Formica M, Cavagnaro L, Basso M, Zanirato A, Felli L, Formica C (2015) Is it possible to preserve lumbar lordosis after hybrid stabilization? Preliminary results of a novel rigid-dynamic stabilization system in degenerative lumbar pathologies. Eur Spine J 24(Suppl 7):S849-S854. doi:10.1007/s00586-015-4264-8

69. Wang JC, Arnold PM, Hermsmeyer JT, Norvell DC (2012) Do lumbar motion preserving devices reduce the risk of adjacent segment pathology compared with fusion surgery? A systematic review. Spine (Phila Pa 1976) 37(22 Suppl):S133-S143. doi:10. 1097/BRS.0b013e31826cadf2

70. Formica M, Cavagnaro L, Zanirato A, Felli L, Formica C (2016) Proximal junctional spondylodiscitis after pedicle subtraction osteotomy. Spine J 16(2):e49-e51. doi:10.1016/j.spinee.2015.09. 050 